\title{
Efficacy of Aclidinium Bromide According to Baseline Therapy: Post-Hoc Analysis of ASCENT-COPD Randomized Trial
}

\author{
Robert A. Wise (D) - Benjamin M. Scirica - Deepak L. Bhatt • \\ Sami Z. Daoud · Ferran Chuecos · Esther Garcia Gil · Kenneth R. Chapman
}

Received: May 6, 2021 / Accepted: July 29, 2021 / Published online: September 15, 2021

(C) The Author(s) 2021

\section{ABSTRACT}

Introduction: Long-acting muscarinic antagonists (LAMAs), long-acting $\beta_{2}$-agonists (LABAs), inhaled corticosteroids (ICS), and their combinations, are recommended for the treatment of

Supplementary Information The online version contains supplementary material available at https:// doi.org/10.1007/s12325-021-01878-5.

R. A. Wise $(\bowtie)$

Pulmonary and Critical Care, Johns Hopkins University School of Medicine, 5501 Hopkins Bayview Circle, Baltimore, MD 21224, USA e-mail: rwise@jhmi.edu

B. M. Scirica - D. L. Bhatt

Brigham and Women's Hospital, Boston, MA, USA

B. M. Scirica - D. L. Bhatt

Harvard Medical School, Boston, MA, USA

S. Z. Daoud

Late-Stage Respiratory and Immunology,

BioPharmaceuticals R\&D, AstraZeneca,

Gaithersburg, MD, USA

F. Chuecos

Late-Stage Development, Respiratory and

Immunology-Biometrics, BioPharmaceuticals R\&D,

AstraZeneca, Barcelona, Spain

E. Garcia Gil

Respiratory and Immunology, BioPharmaceuticals

Medical, AstraZeneca, Barcelona, Spain

K. R. Chapman

University of Toronto, Toronto, ON, Canada chronic obstructive pulmonary disease (COPD). This study aimed to determine whether the safety and efficacy of aclidinium bromide differs by baseline maintenance LABA and ICS therapies.

Methods: ASCENT-COPD was a phase 4, multicenter, double-blind, randomized, placebocontrolled, parallel-group study of patients with moderate-to-very severe COPD and increased cardiovascular risk. Patients were randomized $1: 1$ to receive aclidinium $400 \mu \mathrm{g}$ or placebo twice daily, via a multidose dry-powder inhaler for up to 3 years. Outcomes included time to first major adverse cardiovascular events (MACE), all-cause mortality, change from baseline in trough forced expiratory volume in $1 \mathrm{~s}$ $\left(\mathrm{FEV}_{1}\right)$, and COPD assessment test (CAT) total score over 3 years, and annual moderate-tosevere COPD exacerbation rate in patients receiving aclidinium or placebo with maintenance LABA monotherapy, ICS monotherapy, LABA + ICS (fixed/free), or no maintenance therapy (neither LABA nor ICS) at baseline.

Results: A total of 3589 patients were included (LABA, $n=227 ; \quad$ ICS,$n=290 ; \quad$ LABA + ICS, $n=2058$; no maintenance, $n=1130$ ). Aclidinium did not increase the risk of MACE or allcause mortality versus placebo, regardless of baseline maintenance treatment. Reductions in moderate-to-severe exacerbation rates were observed with aclidinium versus placebo in all subgroups [LABA $43 \% \quad(P=0.046) ;$ ICS $25 \%$ $(P=0.202) ; \quad$ LABA + ICS $22 \% \quad(P=0.003) ;$ no 
maintenance $18 \% \quad(P=0.130)]$. Aclidinium improved morning trough $\mathrm{FEV}_{1}$ irrespective of baseline therapy and CAT total scores, except for LABA and ICS subgroups, versus placebo at several time points.

Conclusion: In patients with moderate-to-severe COPD and CV risk factors, the addition of aclidinium to maintenance therapy with LABA or LABA + ICS provided further benefit.

Trial Registration: ClinicalTrials.gov identifier NCT01966107.

Keywords: Aclidinium bromide; Chronic obstructive pulmonary disease; Muscarinic antagonists

\section{Key Summary Points}

Why carry out this study?

Exacerbations of chronic obstructive pulmonary disease (COPD) are associated with accelerated loss of lung function, increased risk of major adverse cardiovascular events (MACE), and decreased survival

This post-hoc analysis of ASCENT-COPD evaluated whether aclidinium provided an added benefit in reducing the risk of moderate-to-severe exacerbation in patients with moderate-to-very severe COPD and elevated risk of cardiovascular (CV) events who were already taking other maintenance therapies at baseline. We also wanted to know whether aclidinium was associated with differential risk of MACE or all-cause mortality in patients who were already taking other maintenance therapies at baseline

What was learned from the study?

Aclidinium is effective in reducing rates of moderate-to-severe exacerbation in patients with stable, moderate-to-severe COPD, and CV risk factors, regardless of baseline maintenance therapy
Aclidinium did not increase the risk of

MACE or all-cause mortality versus

placebo, regardless of baseline

maintenance therapy

There is benefit in adding aclidinium to commonly prescribed maintenance therapies for patients with moderate-tosevere COPD

\section{INTRODUCTION}

Chronic obstructive pulmonary disease (COPD) is a leading global cause of morbidity and mortality [1-3]. COPD is independently associated with cardiovascular (CV) diseases, such as ischemic heart disease and heart failure, which contribute significantly to all-cause mortality $[4,5]$. Exacerbations of COPD are significant events that are associated with increased disease progression, including decreased lung function $[6,7]$, increased risk of major adverse cardiovascular events (MACE) [8-11], and increased mortality [12-14].

Long-acting muscarinic antagonists (LAMAs), long-acting $\beta_{2}$-agonists (LABAs), and combinations of the two are recommended for the maintenance treatment of stable COPD [1]. Both LAMAs and LABAs improve lung function and dyspnea; however, evidence suggests that LAMAs have a greater impact on exacerbations [15-18]. The addition of inhaled corticosteroids (ICS) to LABA/LAMA combinations may be considered for the treatment of patients with persistent symptoms and recurrent exacerbations [1].

Two recent post-hoc studies (WISDOM and IMPACT) have demonstrated that clinical efficacy and safety outcomes vary in COPD subgroups, based on their baseline maintenance treatment $[19,20]$. In both studies, patients with COPD and a history of exacerbations receiving triple therapy at baseline had an increased risk of moderate-to-severe exacerbations versus the overall population or patients receiving dual therapy at baseline or LAMA monotherapy. This would perhaps be expected given that triple therapy is currently recommended for those with severe disease [1]. In the 
WISDOM study, withdrawal of ICS did not increase exacerbation risk versus the overall population [20]. In addition, in the IMPACT study, patients receiving triple therapy at baseline, that was maintained throughout the study, had a reduced risk of death versus patients who stepped down to LABA/ICS or LAMA/LABA [19]. Since the reduction versus LAMA/LABA did not achieve significance, this suggests that LAMA may contribute to the survival observed with triple therapy.

There has been some uncertainty regarding the CV safety of LAMAs in patients with COPD [21-25]. However, a recent multicenter, doubleblind, randomized, placebo-controlled, parallelgroup phase 4 study (ASCENT-COPD [NCT01966107]) [26] demonstrated that the LAMA aclidinium bromide was noninferior to placebo for the risk of MACE over 3 years, and reduced the rate of moderate-to-severe COPD exacerbations over 1 year in patients with moderate-to-very severe COPD and at high risk of CV events [27].

Here, we report the results of a post-hoc analysis of the ASCENT-COPD study, evaluating whether aclidinium has an added benefit to patients who were already on other baseline maintenance therapies (ICS alone or in combination with LABA) without an increased safety risk, specifically in terms of the risk of moderate-to-severe exacerbation, MACE, and all-cause mortality.

\section{METHODS}

\section{Study Design}

The methodology and patient population of ASCENT-COPD has been reported in detail previously $[26,27]$. In brief, ASCENT-COPD was a phase 4 , multicenter, double-blind, randomized, placebo-controlled, parallel-group study conducted at 522 sites in the USA and Canada [27]. The study comprised a 2-week washout period followed by a double-blind treatment phase, in which patients were randomized 1:1 to receive aclidinium $400 \mu \mathrm{g}$ or placebo twice daily administered via a multidose dry-powder inhaler (Genuair/Pressair; AstraZeneca) for up to 3 years. The event-driven study was to end when $\geq 122$ patients experienced an adjudicated major adverse CV event.

Protocol and informed consent procedures for the study were approved by the Institutional Review Board at each study site. All patients provided written informed consent and the study was performed in accordance with the Declaration of Helsinki and Good Clinical Practice Guidelines. The ASCENT-COPD study was initially funded by Forest Laboratories and later funded by AstraZeneca and Circassia. AstraZeneca was involved in data collection and interpretation, along with the development and review of this manuscript; however, the decision to submit the manuscript for publication was made by the authors.

\section{Study Population}

Patient eligibility has been described previously [26]. In brief, eligible patients were $\geq 40$ years of age with stable, moderate-to-very severe COPD (forced expiratory volume in $1 \mathrm{~s}$ $\left[\mathrm{FEV}_{1}\right] /$ forced vital capacity $[\mathrm{FVC}]<70 \%$ and FEV $_{1}<80 \%$ predicted) and had a smoking history of $\geq 10$ pack-years. In addition, patients were required to have $\geq 1$ of the following $\mathrm{CV}$ risk factors: cerebrovascular disease (e.g., stroke or transient ischemic attack and/or carotid stenosis); coronary artery disease (e.g., angioplasty/stent/bypass, angina, and/or myocardial infarction); peripheral vascular disease; or a history of claudication. Alternatively, patients were required to have $\geq 2$ atherothrombotic risk factors, which are detailed in the supplement. Initially, eligible patients had $\geq 1$ COPD exacerbation in the year prior to screening; however, this requirement was removed after approximately half of the patients were enrolled to increase accrual and to allow for a broader patient population. At that time, the upper limit of post-bronchodilator $\mathrm{FEV}_{1}$ was also increased from 70 to $80 \%$ predicted [27].

Patients were excluded if they were receiving triple therapy (ICS/LABA/LAMA) at screening, had a respiratory infection or COPD exacerbation $\leq 4$ weeks prior to screening, had unstable or life-threatening COPD or CV disease, had a comorbid lung disease other than COPD, had 


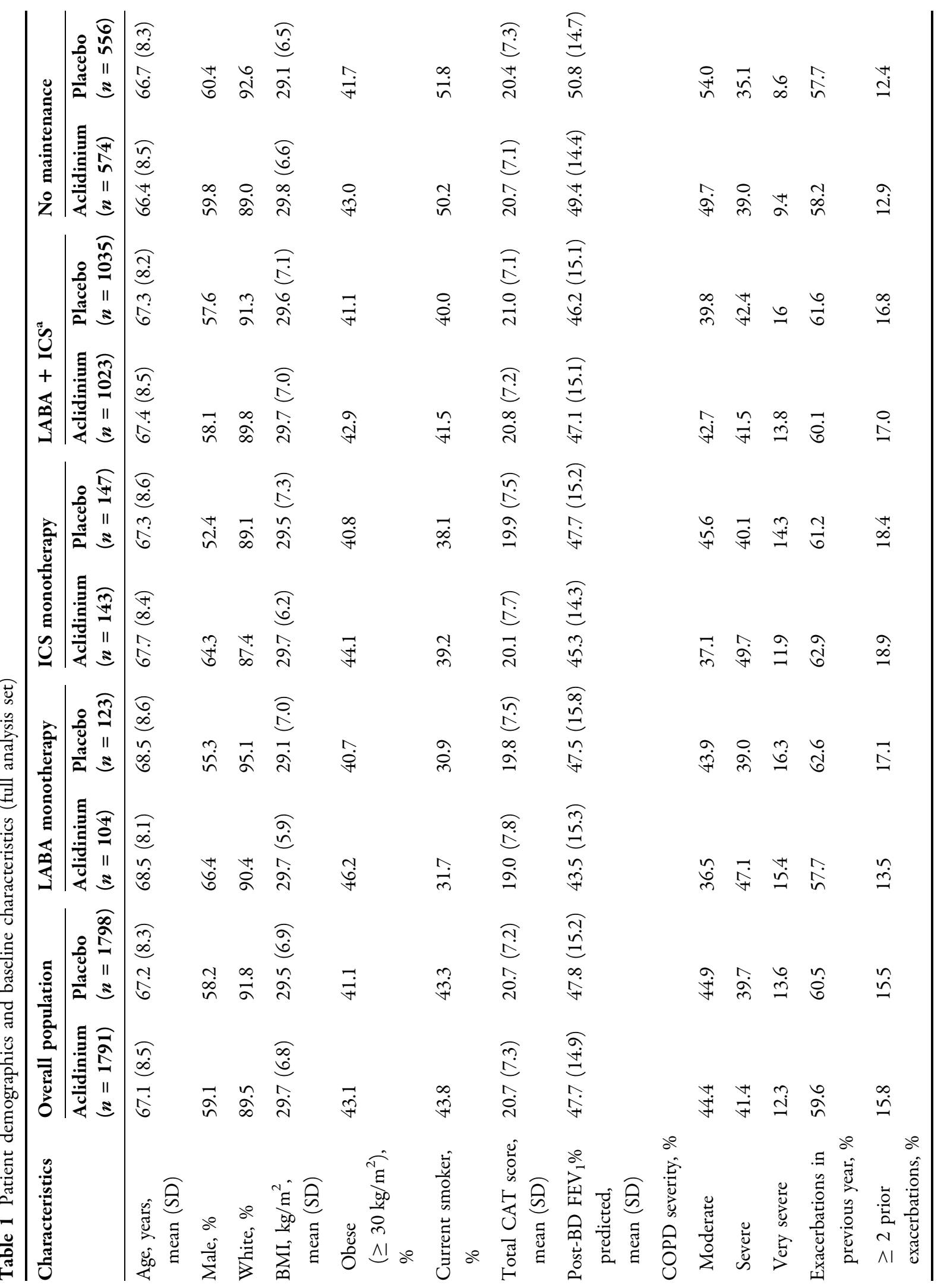




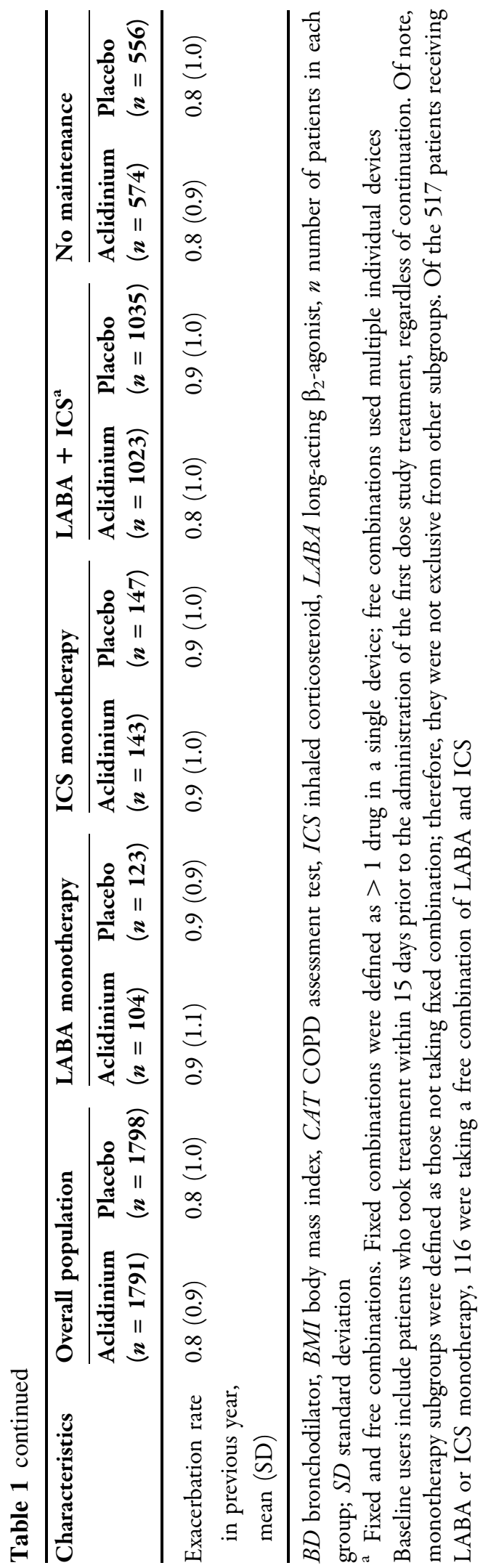

a planned lung transplant or a lung volume reduction surgery, or had malignancy requiring intervention $\leq 5$ years prior to screening [26].

Concomitant use of other COPD medications was permitted (including a LABA with or without an ICS), except for anticholinergics and chronic treatment with regularly scheduled short-acting $\beta_{2}$-agonists, such as albuterol or salbutamol. Episodic use of sponsor-provided albuterol/salbutamol was permitted, except for within $6 \mathrm{~h}$ prior to any visit. Oral or parenteral corticosteroids were permitted, provided the patient was stable for $\geq 2$ weeks before screening; however, they may have been initiated, or the dose may have changed during the study, only at the discretion of the investigator [26].

\section{Outcomes}

This study performed two subgroup analyses: a post-hoc analysis on baseline maintenance therapy use and a pre-specified analysis based on concomitant maintenance therapy use. Baseline users were defined as patients who took treatment within 15 days prior to the administration of the first dose of study treatment (Fig. S1), regardless of continuation. Of note, monotherapy subgroups were defined as those not taking a fixed combination, but may have been taking free combination; therefore, they were not excluded from other subgroups. The post-hoc analysis assessed time to first MACE, all-cause mortality risk and COPD mortality risk over 3 years, annual moderate-to-severe COPD exacerbation rate, annual severe COPD exacerbation rate, change from baseline in morning pre-dose trough $\mathrm{FEV}_{1}$, and COPD assessment test (CAT) total score over 3 years, in patients receiving aclidinium or placebo with maintenance LABA monotherapy (alone or in free combination with ICS), ICS monotherapy (alone or in free combination with LABA), LABA with ICS (LABA + ICS, fixed and free combinations), and no maintenance therapy (neither LABA nor ICS) at baseline. Concomitant users include patients who initiated treatment prior to randomization and continued beyond the first dose of study treatment (Fig. S1). The prespecified subgroup analysis assessed the annual 
moderate-to-severe exacerbation rate, a primary outcome, change from baseline in trough $\mathrm{FEV}_{1}$, and CAT total score over 3 years in patients receiving aclidinium versus placebo and concomitant treatment with LABA with or without ICS ( \pm ICS, fixed and free combinations) and LABA + ICS (fixed and free combinations). Exacerbations were defined as increased COPD symptoms lasting $\geq 2$ days that required treatment with antibiotics and/or systemic corticosteroids, or led to hospitalization or death [27].

\section{Statistical Analyses}

The full analysis set included all patients randomized to treatment who received $\geq 1$ dose of the study treatment [26]. Time to first MACE, all-cause mortality, and COPD mortality were analyzed using Cox proportional hazard models with randomized treatment group (aclidinium/placebo), baseline $\mathrm{CV}$ risk group ( $\geq 2 \mathrm{CV}$ risk factors or $\geq 1$ non-fatal stroke or non-fatal myocardial infarction), smoking status, and baseline treatment (LABA monotherapy/ICS monotherapy/LABA + ICS/ no maintenance therapy) as factors, and the interaction between baseline treatment and randomized treatment group for time to first MACE. The rate of moderate-to-severe COPD exacerbations and severe exacerbations was analyzed using a negative binomial regression model with treatment group, baseline ICS use, baseline COPD severity, history of $\geq 1$ exacerbation in the past year, and smoking status as factors. Changes from baseline in trough $\mathrm{FEV}_{1}$ and CAT total scores were analyzed using a mixed model for repeated measures (MMRM) with corresponding baseline values as covariates, plus pre- and post-bronchodilator (albuterol/salbutamol) $\mathrm{FEV}_{1}$ at screening visit as a covariate for trough $\mathrm{FEV}_{1}$, and treatment group, smoking status, baseline ICS use, visit, and treatment-group-by-visit interaction as fixed effect factors for both.

The subgroups included in this study were analyzed separately in some end points. Testing was performed at the 0.05 significance level for all end points [26]; however, $P$ values were not corrected for multiplicity, and therefore only nominal statistical significance could be inferred if $P<0.05$.

\section{RESULTS}

\section{Baseline Demographics and Characteristics}

Of 3589 patients included in the full analysis set (aclidinium, $n=1791$; placebo, $n=1798$ ), 227 (6.3\%) received LABA monotherapy, 290 (8.1\%) received ICS monotherapy, 2058 (57.3\%) received LABA + ICS, and 1130 (31.5\%) received no maintenance therapy (neither LABA nor ICS) at baseline (Fig. S2a). Of note, of the 517 patients receiving LABA or ICS monotherapy, 116 were taking a free combination of LABA and ICS. A higher percentage of patients receiving no maintenance therapy at baseline were smokers $(51.0 \%)$ and had moderate COPD $(51.8 \%)$ versus other treatment subgroups (smoking: LABA monotherapy 31.3\%; ICS monotherapy $38.6 \%$; LABA + ICS 40.8\%; moderate COPD: LABA monotherapy $40.5 \%$; ICS monotherapy $41.4 \%$; LABA + ICS $41.3 \%$ ). In addition, the percentage of patients experiencing $\geq 2$ exacerbations in the previous year was higher in those using ICS monotherapy (18.6\%) versus other treatment subgroups (LABA monotherapy $15.4 \%$; LABA + ICS $16.9 \%$; no maintenance therapy 12.7\%). Of note, $2243(62.5 \%)$ and 2016 (56.2\%) patients received concomitant treatment (treatment initiated prior to randomization and continued beyond the first dose of study treatment; Fig. S2b) with LABA ( \pm ICS) and LABA + ICS, respectively. Patient demographics and baseline characteristics were similar between patients receiving aclidinium and placebo (Table 1 ).

\section{Safety}

Aclidinium did not increase the risk of MACE or all-cause mortality compared with placebo, regardless of maintenance treatment at baseline (Figs. 1 and 2). Of note, only a small number of events were observed for patients receiving LABA monotherapy and ICS monotherapy at 
(a)
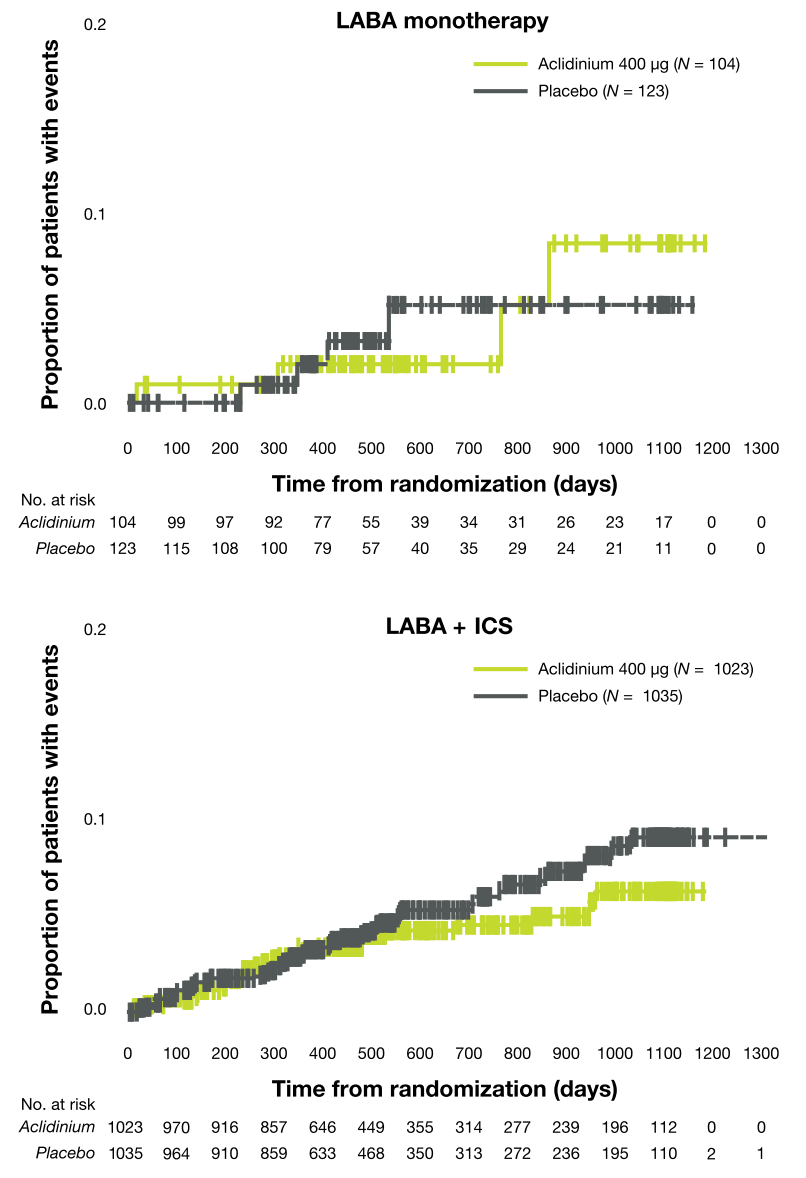

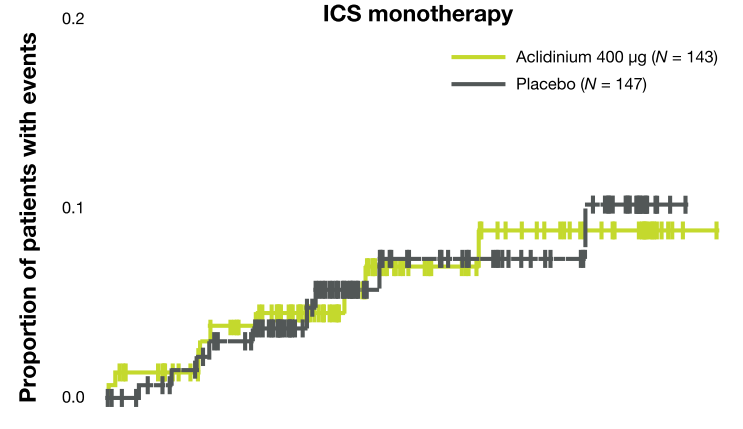

$\begin{array}{llllllllllllll}0 & 100 & 200 & 300 & 400 & 500 & 600 & 700 & 800 & 900 & 1000 & 1100 & 1200 & 1300\end{array}$ No. at risk Time from randomization (days)

$\begin{array}{lllllllllllllll}\begin{array}{l}\text { No. at risk } \\ \text { Aclidinium }\end{array} & 143 & 137 & 126 & 120 & 99 & 81 & 60 & 52 & 44 & 39 & 34 & 22 & 1 & 0\end{array}$ $\begin{array}{lllllllllllllll}\text { Placebo } & 147 & 140 & 131 & 124 & 96 & 72 & 52 & 47 & 41 & 36 & 30 & 15 & 0 & 0\end{array}$

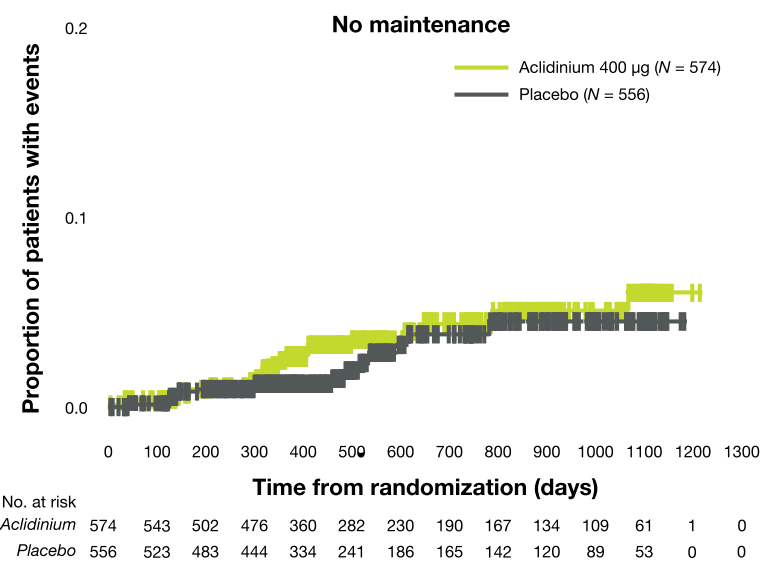

(b)

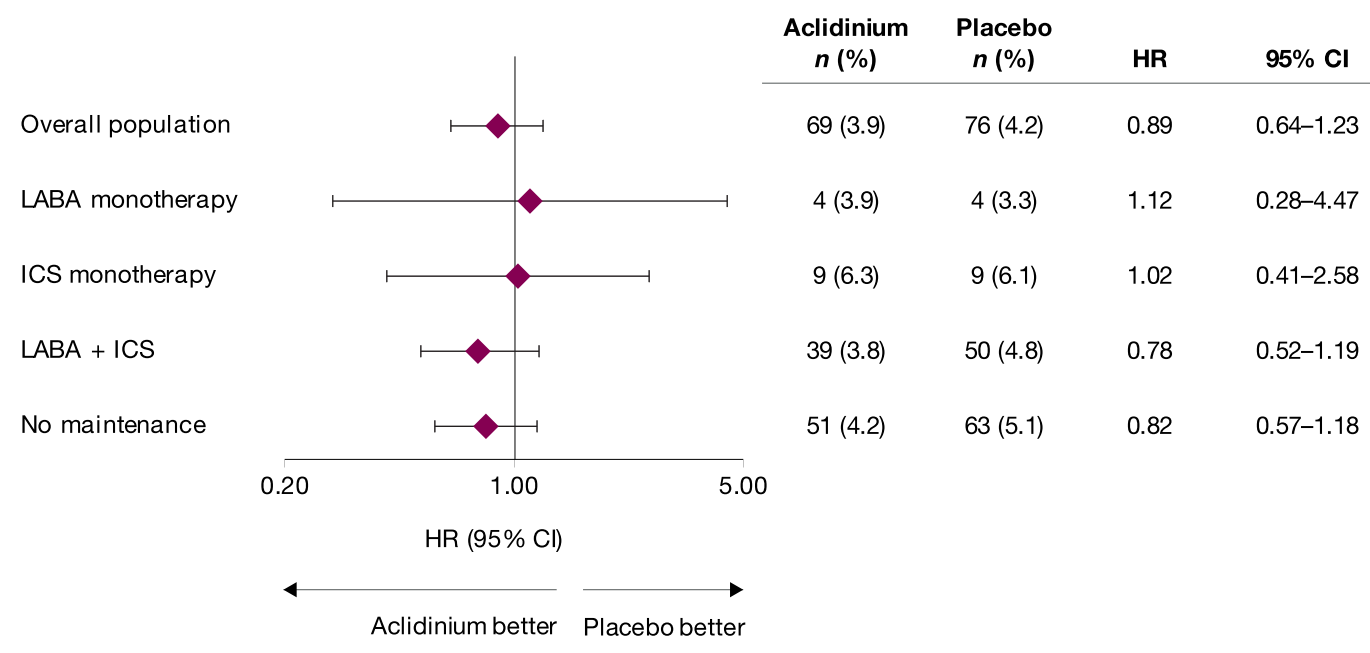


4 Fig. 1 a Time to first adjudicated MACE and $\mathbf{b}$ the risk of MACE on study, by patient baseline treatment subgroup. $C I$ confidence interval, $C V$ cardiovascular, $H R$ hazard ratio, ICS inhaled corticosteroid, LABA long-acting $\beta_{2}$-agonist, $n$ number of patients in the analysis, $N$ number of patients in the treatment group. Data derived using the Cox proportional hazard regression model with treatment group, baseline CV risk, smoking status, and baseline treatment use as factors, and the interaction between baseline treatment use and treatment group. Baseline users include patients who took treatment within 15 days prior to the administration of the first dose study treatment, regardless of continuation

baseline, likely due to the low numbers in these subgroups. The percentage of deaths was numerically higher for patients receiving ICS monotherapy at baseline for aclidinium versus placebo (9.8\% versus $5.4 \%$, respectively); however, differences were not statistically significant. In addition, there was no increase in the risk of COPD mortality across baseline treatments for aclidinium versus placebo, although event numbers were low [LABA monotherapy: HR 1.2; 95\% CI 0.08, 19.21 (aclidinium, $n=1$; placebo, $n=1$ ); ICS monotherapy: HR data not calculable (aclidinium, $n=3$; placebo, $n=0$ ); LABA + ICS: HR 0.81; 95\% CI 0.37, 1.78 (aclidinium, $n=11$; placebo, $n=14$ ); no maintenance: HR 0.61; 95\% CI 0.10, 3.68 (aclidinium, $n=2$; placebo, $n=3)$ ].

\section{Efficacy}

Reductions in the rate of moderate-to-severe COPD exacerbations during the first year were observed with the addition of aclidinium versus placebo in all treatment subgroups. The magnitude of reduction due to aclidinium treatment was similar to that observed in the overall population $(22 \%)$ for patients receiving ICS monotherapy, LABA + ICS, and no maintenance therapy at baseline $(25 \%, 22 \%$, and $18 \%$, respectively; Fig. 3) and greater than the overall population for patients receiving LABA monotherapy at baseline (43\%). The reductions in moderate-to-severe COPD exacerbation rate with additional aclidinium versus placebo were significant for patients receiving LABA monotherapy and LABA + ICS at baseline ( $P=0.046$ and $P=0.003$, respectively) and were numerically lower, but not nominally significant, for patients receiving ICS monotherapy and no maintenance therapy at baseline. Of note, although the mean moderate-to-severe exacerbation event rates in the aclidinium treatment arm were similar for all baseline treatment subgroups (ranging from 0.43 to 0.49 ), the mean moderate-to-severe exacerbation event rate for patients receiving placebo was lower for those not receiving maintenance therapy (0.53) versus other treatment subgroups (ranging from 0.60 to 0.77 ). Rates of severe COPD exacerbations demonstrated a similar pattern of reductions across baseline maintenance treatment groups for aclidinium versus placebo as those seen with moderate-to-severe COPD exacerbations; however, due to a low number of events, only patients receiving LABA + ICS at baseline had a nominally significant reduction in rates $(31 \% ; P=0.048)$.

In addition, for patients who took concomitant LABA with or without ICS ( \pm ICS) and LABA + ICS during the first year of treatment, those additionally treated with aclidinium had a $23 \%$ reduction in the annual rate of moderateto-severe COPD exacerbations versus placebo [rate ratio (RR), 0.77 [95\% confidence interval (95\% CI) 0.66-0.89] and RR, 0.77 (95\% CI 0.60-0.90), respectively; $P<0.001$; Fig. S3].

Aclidinium provided improvements from baseline in trough $\mathrm{FEV}_{1}$ versus placebo at most time points, with nominally significant improvements over the whole first year for all subgroups except those receiving LABA and ICS monotherapy at baseline (Fig. 4). In general, the addition of aclidinium to LABA monotherapy provided a lower treatment effect on trough $\mathrm{FEV}_{1}$ versus other baseline treatment subgroups; however, this subgroup had the lowest number of patients and wide CI values. For the other treatment subgroups, improvements were generally comparable with those observed in the overall population. In addition, for patients who received concomitant LABA $( \pm$ ICS) and LABA + ICS over the entire study period, adding aclidinium improved lung function versus placebo over the first year (both $P<0.001$; 
(a)

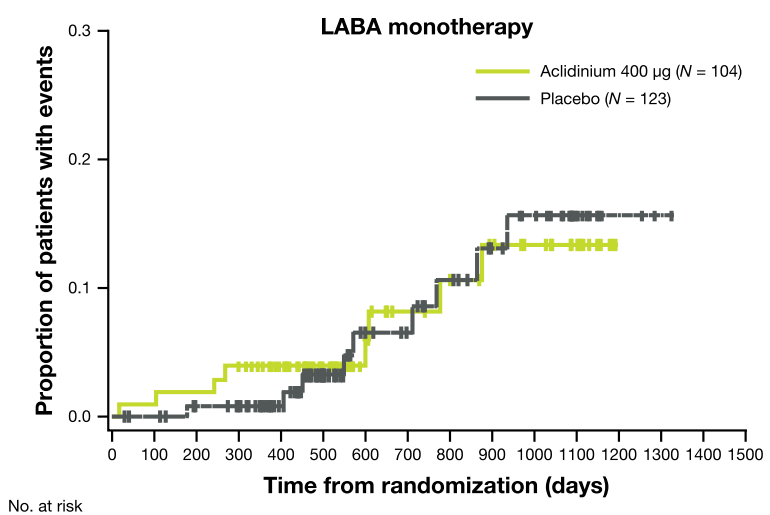

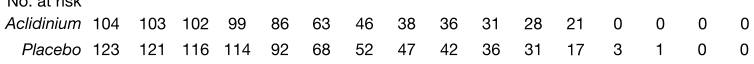

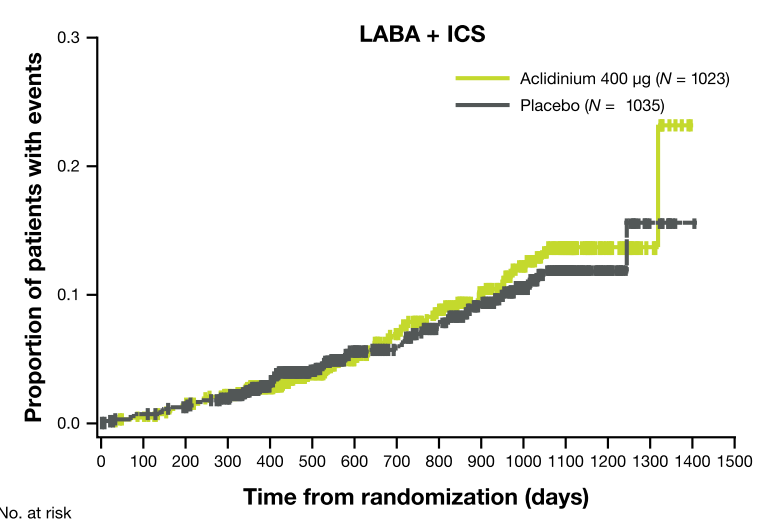

Aclidinium $1023 \quad 1011995 \quad 973 \quad 760 \begin{array}{llllllllllll}548 & 449 & 409 & 372 & 320 & 280 & 175 & 31 & 11 & 0 & 0\end{array}$

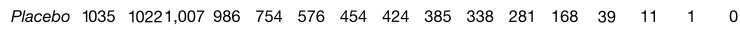

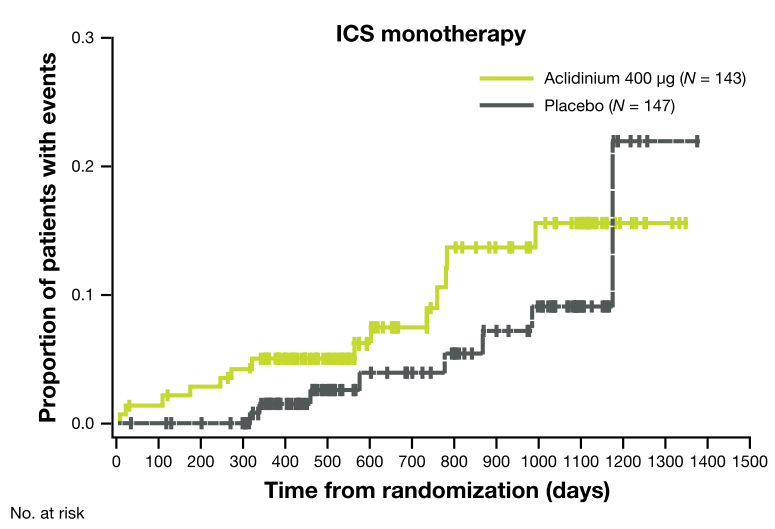

$\begin{array}{lllllllllllllllll}\begin{array}{l}\text { No. at risk } \\ \text { Aclidinium }\end{array} & 143 & 140 & 137 & 134 & 112 & 94 & 72 & 61 & 55 & 50 & 45 & 32 & 7 & 3 & 0 & 0 \\ \text { Placebo } & 147 & 146 & 142 & 139 & 108 & 86 & 70 & 64 & 59 & 53 & 47 & 25 & 4 & 1 & 0 & 0\end{array}$

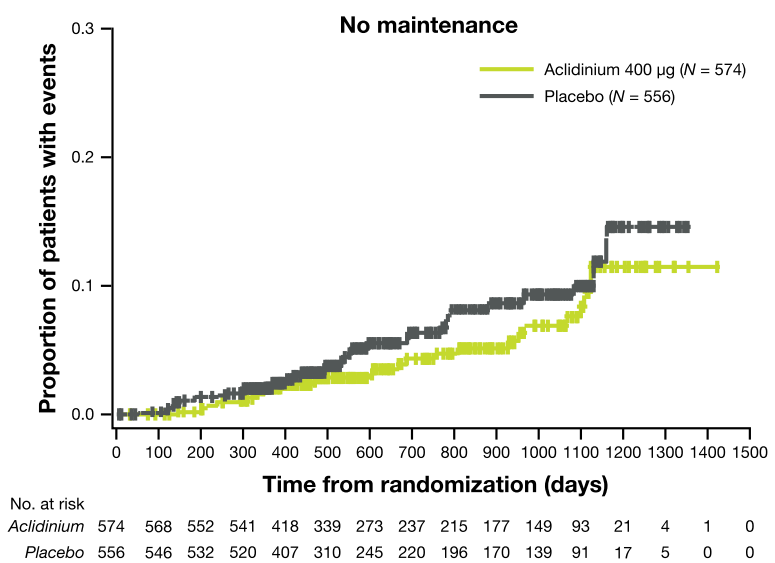

(b)

\begin{tabular}{|c|c|c|c|c|c|c|}
\hline & & & $\begin{array}{c}\text { Aclidinium } \\
n(\%)\end{array}$ & $\begin{array}{c}\text { Placebo } \\
n(\%)\end{array}$ & HR & $95 \% \mathrm{Cl}$ \\
\hline Overall population & $\longmapsto$ & & $116(6.5)$ & $118(6.6)$ & 0.99 & $0.76-1.28$ \\
\hline LABA monotherapy & 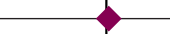 & & $8(7.7)$ & $9(7.3)$ & 1.02 & $0.39-2.64$ \\
\hline ICS monotherapy & $\longmapsto$ & -1 & $14(9.8)$ & $8(5.4)$ & 1.76 & $0.74-4.21$ \\
\hline LABA + ICS & $\longmapsto$ & & $73(7.1)$ & $69(6.7)$ & 1.09 & $0.79-1.52$ \\
\hline No maintenance & $\rightarrow$ & & $27(4.7)$ & $34(6.1)$ & 0.76 & $0.46-1.25$ \\
\hline 0.20 & 1.00 & 5.00 & & & & \\
\hline & HR $(95 \%$ Cl) & & & & & \\
\hline
\end{tabular}


4Fig. 2 a Time to death and $\mathbf{b}$ risk of all-cause mortality on study, by patient baseline treatment subgroup. CI confidence interval, $C V$ cardiovascular, $H R$ hazard ratio, ICS inhaled corticosteroid, $L A B A$ long-acting $\beta_{2}$-agonist, $n$ number of patients in the analysis, $N$ number of patients in the treatment group. Data derived using the Cox proportional hazard regression model with treatment group, baseline CV risk, smoking status, and baseline treatment use as factors. Baseline users include patients who took treatment within 15 days prior to the administration of the first dose study treatment, regardless of continuation

Fig. S4). The treatment effect of aclidinium was sustained beyond 1 year in some subgroups; however, patient numbers were small so results should be interpreted with caution.

While improvements were not nominally significant, numerical improvements from baseline in CAT total score were observed at most time points with aclidinium versus placebo, except where patients were receiving maintenance LABA or ICS monotherapy at baseline (Fig. 5); however, results for the LABA and ICS monotherapy subgroups, and all subgroup results observed beyond the first year, should be interpreted with caution due to small patient numbers. Numerical improvements were also observed with aclidinium versus placebo in the overall population, up to week 130. Similarly, in patients who received concomitant LABA ( \pm ICS) and LABA + ICS over the entire study period, adding aclidinium numerically improved CAT total score versus placebo at all but one time point (Fig. S5).

\section{DISCUSSION}

Further to the results of the primary analysis of the ASCENT-COPD study, in which aclidinium treatment was not associated with an increased risk of MACE versus placebo [27], this post-hoc analysis did not find an increased risk of MACE or all-cause mortality with aclidinium versus placebo, regardless of the maintenance baseline therapy. A small numerical increase in all-cause mortality was observed with aclidinium versus placebo for patients receiving ICS monotherapy at baseline; however, this increase in mortality was not evident in the larger subgroup of patients receiving maintenance ICS/LABA at baseline [28]. Of note, ICS monotherapy is not

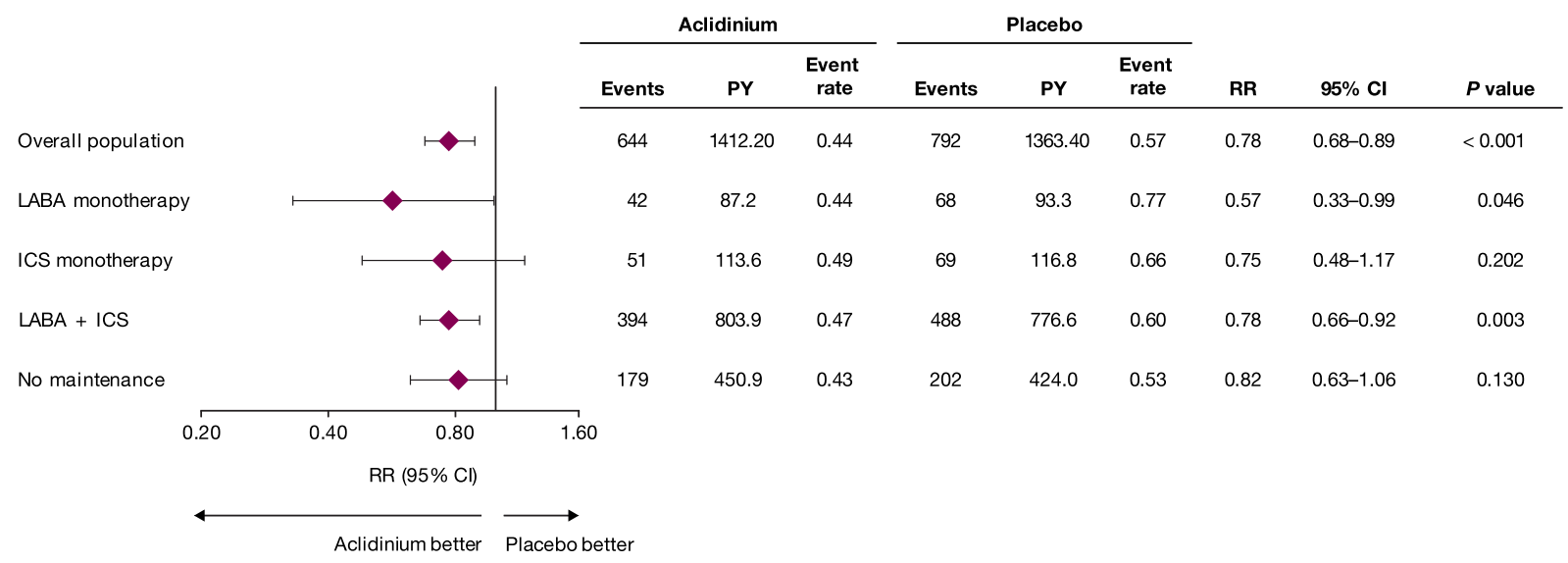

Fig. 3 Moderate-to-severe COPD exacerbations during the first year, by patient baseline treatment subgroup (ontreatment). $C I$ confidence interval, COPD chronic obstructive pulmonary disease, $I C S$ inhaled corticosteroid, $L A B A$ long-acting $\beta_{2}$-agonist, $P Y$ patient-years, $R R$ rate ratio. Data derived using the negative binomial regression model with treatment group, baseline ICS use, baseline year, and smoking status as factors, and the log of the exposure time adjusted for the time patients experience exacerbations as an offset variable. Baseline users include patients who took treatment within 15 days prior to the administration of the first dose study treatment, regardless of continuation 
(a)

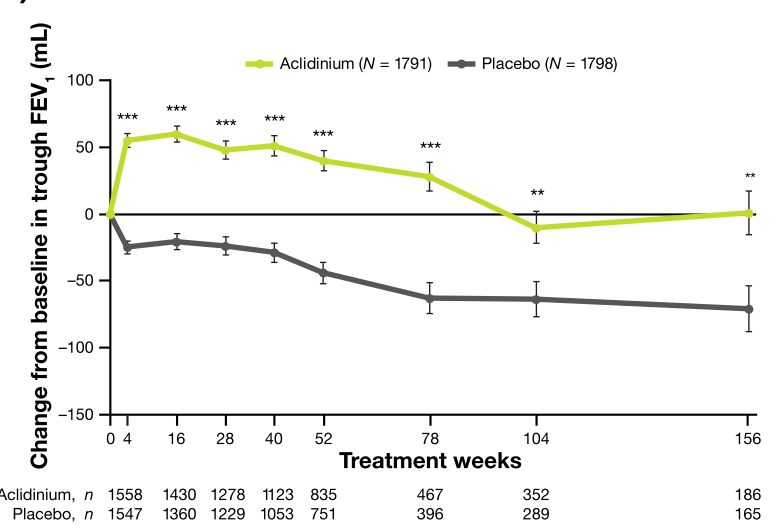

(c)

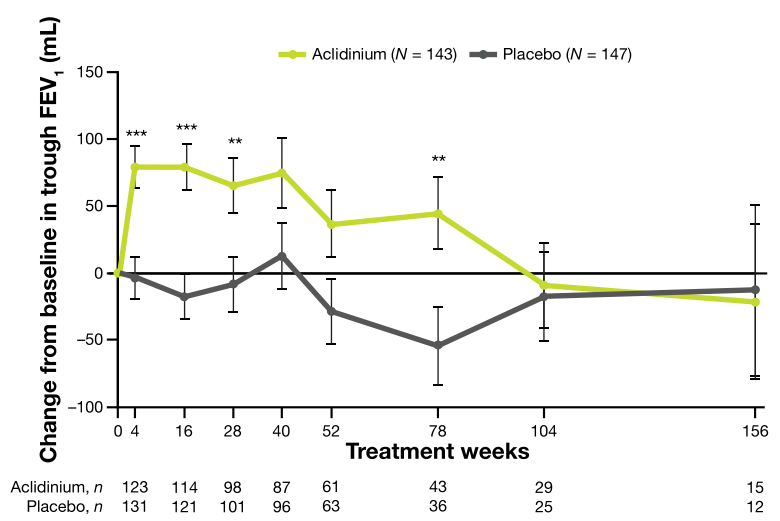

(b)

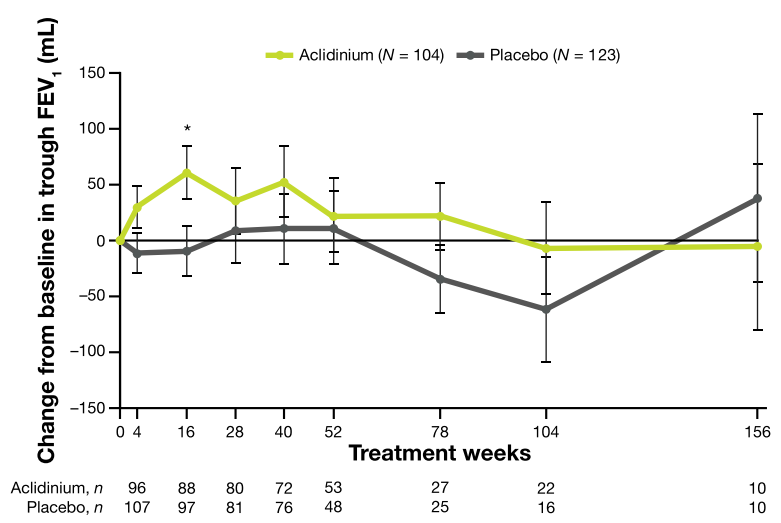

(d)

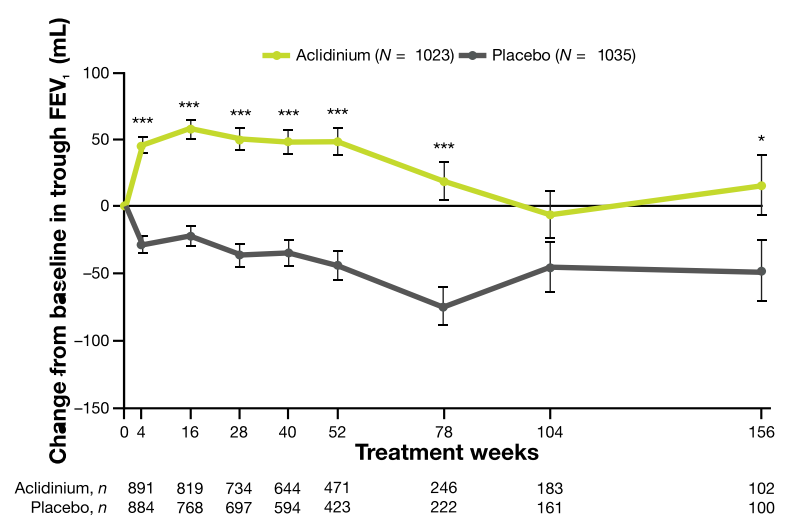

(e)

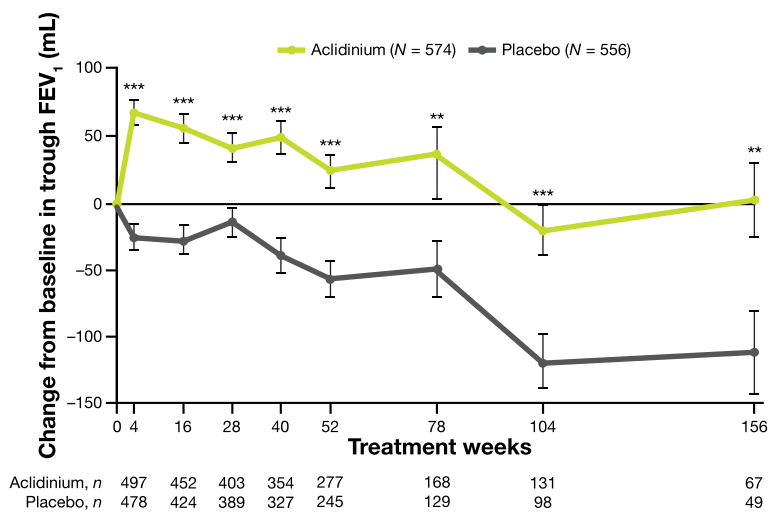


4Fig. 4 Change from baseline in trough $\mathrm{FEV}_{1}$ over 156 weeks in a overall population, b patients receiving LABA monotherapy at baseline, $\mathbf{c}$ patients receiving ICS monotherapy at baseline, $\mathbf{d}$ patients receiving LABA + ICS at baseline, and e patients not receiving maintenance therapy at baseline. $F E V_{1}$ forced expiratory volume in $1 \mathrm{~s}$, $I C S$ inhaled corticosteroid, $L A B A$ long-acting $\beta_{2}$-agonist, $M M R M$ mixed model for repeated measures, $n$ number of patients in the analysis, $N$ number of patients in the treatment group. ${ }^{*} P<0.05,{ }^{* *} P<0.01,{ }^{* * *} P<0.001$ for aclidinium versus placebo. Data are least squares means \pm standard error. The analysis was based on an MMRM for change from baseline in trough $\mathrm{FEV}_{1}$ with pre- and post-bronchodilator (albuterol/salbutamol) $\mathrm{FEV}_{1}$ at screening visit and baseline $\mathrm{FEV}_{1}$ as covariates, and treatment group, smoking status, baseline ICS use, visit, and treatment-group-by-visit interaction as fixed effect factors. Visit is fitted as a categorical variable, and the variance-covariance matrix is assumed to be unstructured. Week 156 includes assessments from patients who completed 3 years treatment or who were on-treatment when the study was stopped. Baseline users include patients who took treatment within 15 days prior to the administration of the first dose study treatment, regardless of continuation

recommended for COPD maintenance therapy [1]. Furthermore, only a small number of deaths were observed for patients receiving ICS monotherapy, LABA monotherapy, or no maintenance therapy at baseline and, therefore, these results should be interpreted with caution. Similarly, there was no increase in COPD mortality for patients receiving aclidinium versus placebo across treatment subgroups.

Aclidinium provided nominally significant reductions in the rate of moderate-to-severe exacerbations versus placebo over the first year for patients receiving LABA monotherapy or LABA + ICS at baseline. Numerical improvements in exacerbation rates were also observed for patients using ICS monotherapy or no maintenance therapy at baseline, which likely did not achieve significance because of the small number of patients in the ICS monotherapy subgroup, given the significant improvement observed in the LABA + ICS subgroup, and a comparatively low exacerbation rate in the placebo arm of the no maintenance therapy subgroup. Across treatment subgroups, only patients receiving baseline treatment with LABA + ICS demonstrated improvements in rates of severe exacerbations for patients receiving aclidinium versus placebo.

Improved lung function versus placebo was also observed throughout the first year for patients receiving ICS monotherapy, LABA + ICS, or no maintenance therapy at baseline; however, aclidinium appeared to provide minimal additional benefit to patients receiving LABA monotherapy at baseline versus other treatment subgroups. Of note, these results should be interpreted with caution since patient numbers in the monotherapy subgroups, and other treatments beyond the first year, were too small to draw meaningful conclusions. In addition, numerical improvements from baseline in patient-reported health-related quality of life (HRQoL) were observed following further treatment with aclidinium versus placebo for patients receiving LABA + ICS or no maintenance therapy at baseline. No improvement was observed following the addition of aclidinium to LABA and ICS monotherapy subgroups; however, as discussed, these subgroups had small patient numbers and showed high variability.

Similar results were observed for all outcomes measured in patients who were taking concomitant LABA $( \pm$ ICS $)$ and LABA + ICS throughout the study period, with the addition of aclidinium to maintenance treatment resulting in improvements in exacerbation rate, lung function, and HRQoL, versus placebo, providing further evidence that aclidinium provided additional benefit to background LABA therapy.

These results were comparable with a recent subgroup analysis of the FUFIL study, in which LAMA/LABA/ICS improved trough $\mathrm{FEV}_{1}$ and St George's Respiratory Questionnaire total scores versus LABA/ICS, regardless of the medication received at screening, including LABA alone, LAMA + LABA, and LAMA + LABA + ICS [29]. In addition, significant reductions in annual exacerbation rates were observed for LAMA/ LABA/ICS versus LABA/ICS in patients receiving prior LABA + ICS [29]. Similar results were also observed in a systematic review showing that, when compared with LABA alone, combination 
(a)

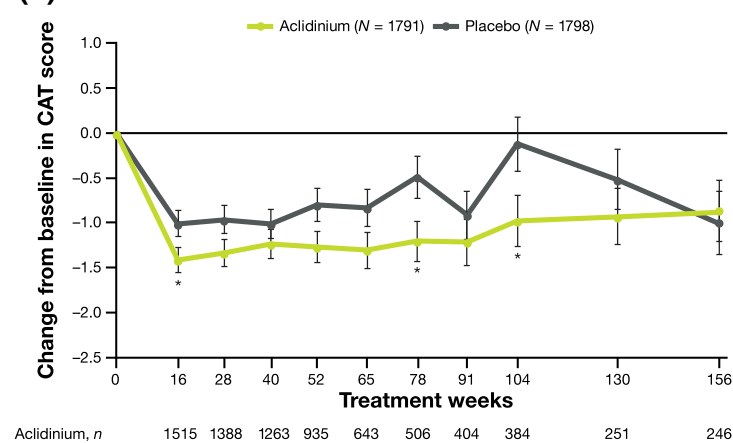

$\begin{array}{ccccccccccc}\text { Aclidinium, } n & 1515 & 1388 & 1263 & 935 & 643 & 506 & 404 & 384 & 251 & 246 \\ \text { Placebo, } n & 1451 & 1322 & 1183 & 862 & 601 & 444 & 367 & 330 & 221 & 232\end{array}$

(c)

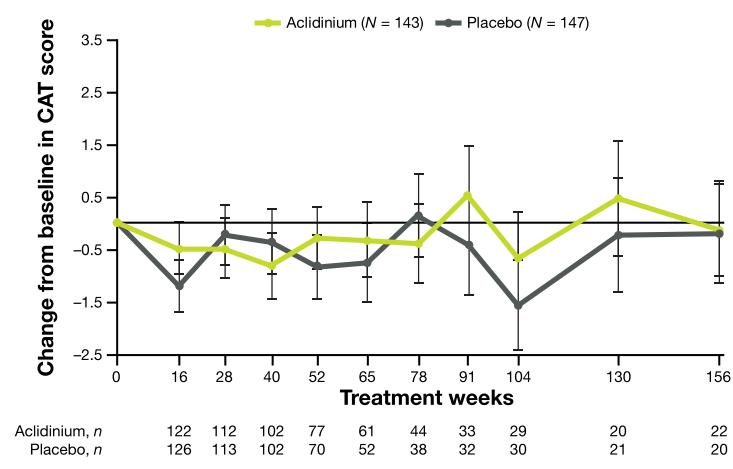

(e)

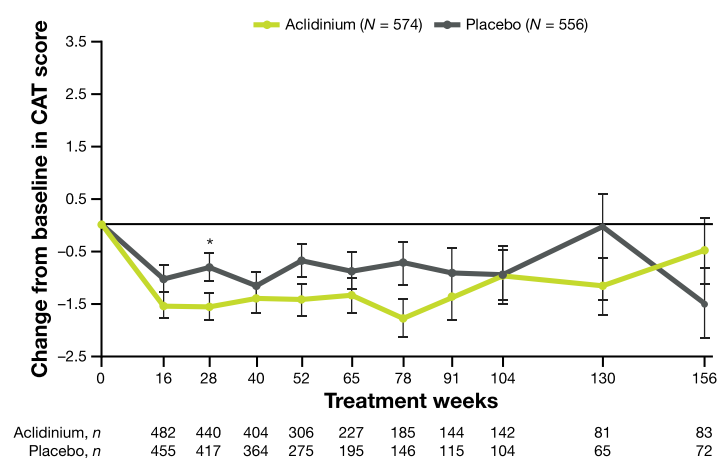

Fig. 5 Change from baseline in CAT total score over 156 weeks in a overall population, $\mathbf{b}$ patients receiving LABA monotherapy at baseline, $\boldsymbol{c}$ patients receiving ICS monotherapy at baseline, $\mathbf{d}$ patients receiving LABA + ICS at baseline, and e patients not receiving maintenance therapy at baseline. CAT COPD assessment test, ICS inhaled corticosteroid, LABA long-acting $\beta_{2}$-agonist, $M M R M$ mixed model for repeated measures, $n$ number of patients in analysis, $N$ number of patients in the treatment group. ${ }^{*} P<0.05$ for aclidinium versus placebo. Data are least squares means \pm standard error. The analysis was based on an MMRM for change from (b)

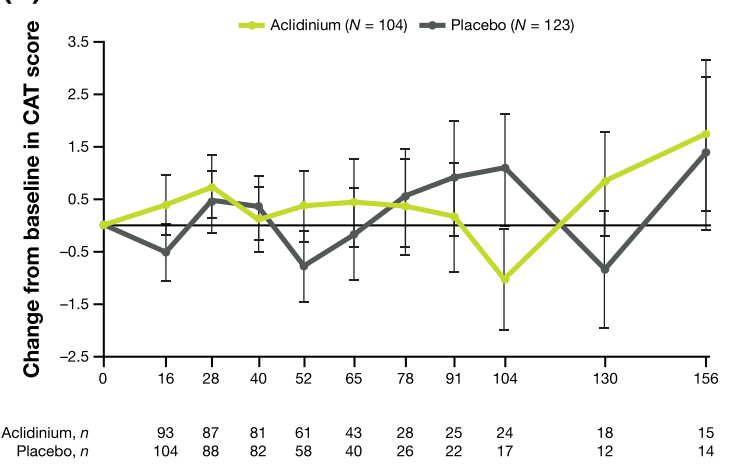

(d)

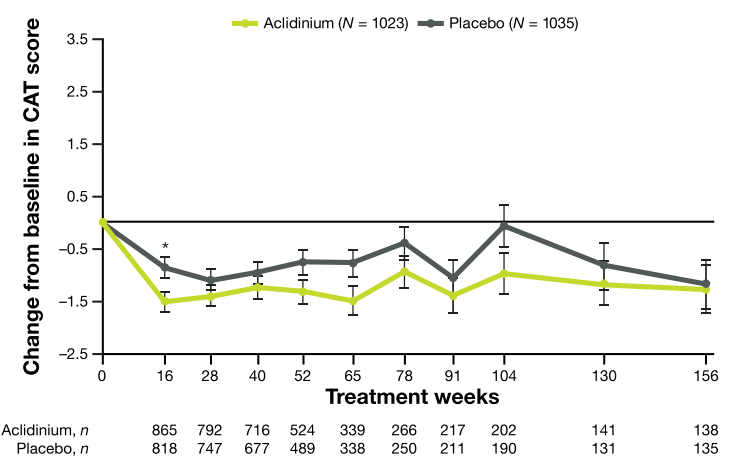

baseline in CAT score with baseline CAT total score as a covariate, and treatment group, smoking status, baseline ICS use, visit, and treatment-group-by-visit interaction as fixed effect factors. Visit is fitted as a categorical variable, and the variance-covariance matrix is assumed to be unstructured. Week 156 includes assessments from patients who completed 3 years treatment or who were on-treatment when the study was stopped. Baseline users include patients who took treatment within 15 days prior to the administration of the first dose study treatment, regardless of continuation 
therapy with aclidinium and LABA significantly reduced exacerbations requiring steroids or antibiotics, and may have improved quality of life (minimal clinically important difference not achieved for either group) with no difference in all-cause mortality [30]. These results support those of the exploratory analysis reported here, that in patients with stable, moderate-to-severe COPD and $\mathrm{CV}$ risk factors, adding aclidinium to maintenance therapy with LABA + ICS, and potentially LABA, was beneficial.

Limitations of the current study included the small patient numbers discussed above. Similar to other investigations, we found no evidence of synergy between LABA and LAMA bronchodilators in any of the outcome measures recorded [31]. We cannot rule out a synergistic effect occurring in a subset of patients based on pharmacogenetic differences [32].

\section{CONCLUSION}

In conclusion, this study demonstrated that aclidinium is effective in patients with stable, moderate-to-severe COPD and CV risk factors, regardless of baseline maintenance therapy with LABA monotherapy, ICS monotherapy, LABA + ICS, or no maintenance therapy, and that there is further benefit to adding aclidinium to maintenance therapy with LABA or LABA + ICS, which are commonly prescribed, in this patient population.

\section{ACKNOWLEDGEMENTS}

The authors thank the study participants.

Funding. The ASCENT-COPD study was initially funded by Forest Laboratories and later funded by AstraZeneca and Circassia. AstraZeneca funded the journal's Rapid Service and Open Access Fees.

Medical Writing and/or Editorial Assistance. The authors thank Dan Lythgoe, of Phastar, who provided statistical consultation. Medical writing support was provided by Richard Knight, PhD, and Sarah Hoyle, PhD, of
CMC Connect, McCann Health Medical Communications, and was funded by AstraZeneca, in accordance with Good Publication Practice (GPP3) guidelines.

Authorship. All named authors meet the International Committee of Medical Journal Editors (ICMJE) criteria for authorship for this article, take responsibility for the integrity of the work as a whole, and have given their approval for this version to be published.

Author Contributions. Dr. Wise had full access to all of the data in the study and takes responsibility for the integrity of the data and the accuracy of the data analysis. Concept and design: Wise, Chapman, Scirica, Chuecos, Garcia Gil. Acquisition, analysis, or interpretation of data: All authors. Drafting of the manuscript: Wise, Chapman, Garcia Gil. Critical revision of the manuscript for important intellectual content: All authors. Statistical analysis: Daoud, Chuecos, Garcia Gil. Administrative, technical, or material support: Wise, Chapman, Daoud, Supervision: Wise, Scirica, Daoud, Garcia Gil.

Disclosures . Robert A. Wise reports personal fees from AstraZeneca, during the conduct of the study; personal fees from AbbVie, Anaptsys Bio, Circassia, Contrafect, Galderma, GSK, Kamada, Kinevant, Kiniksa, Merck, Novartis, Pneuma, Propeller Health, Pulmonx, Roche, Sunovion, and Verona; grants from Pearl Therapeutics; and grants and personal fees from AstraZeneca/MedImmune and Boehringer Ingelheim, outside the submitted work. Benjamin M. Scirica reports an institutional research grant to Brigham and Women's Hospital from AstraZeneca, during the conduct of the study; consulting fees from AbbVie, Allergan, AstraZeneca, Boehringer Ingelheim, Eisai, Elsevier Practice Update Cardiology, Esperion, Hamni, Lexicon, Medtronic, Merck, and Novo Nordisk; equity in Health[at]Scale; grants from Eisai, Merck, Novartis, Novo Nordisk, and Pfizer, outside of the submitted work. Deepak L. Bhatt discloses the following relationships - Advisory Board: Cardax, CellProthera, Cereno Scientific, Elsevier Practice Update Cardiology, Janssen, Level Ex, Medscape 
Cardiology, MyoKardia, NirvaMed, Novo Nordisk, PhaseBio, PLx Pharma, and Regado Biosciences; Board of Directors: Boston VA Research Institute, Society of Cardiovascular Patient Care, TobeSoft; Chair: American Heart Association Quality Oversight Committee; Data Monitoring Committees: Baim Institute for Clinical Research (formerly Harvard Clinical Research Institute, for the PORTICO trial, funded by St. Jude Medical, now Abbott), Cleveland Clinic (including for the ExCEED trial, funded by Edwards), Contego Medical (Chair, PERFORMANCE 2), Duke Clinical Research Institute, Mayo Clinic, Mount Sinai School of Medicine (for the ENVISAGE trial, funded by Daiichi Sankyo), and Population Health Research Institute; Honoraria: American College of Cardiology (Senior Associate Editor, Clinical Trials and News, ACC.org; Chair, ACC Accreditation Committee), Baim Institute for Clinical Research (formerly Harvard Clinical Research Institute; RE-DUAL PCI clinical trial steering committee funded by Boehringer Ingelheim; AEGIS-II executive committee funded by CSL Behring), Belvoir Publications (Editor-in-Chief, Harvard Heart Letter), Canadian Medical and Surgical Knowledge Translation Research Group (clinical trial steering committees), Duke Clinical Research Institute (clinical trial steering committees, including for the PRONOUNCE trial, funded by Ferring Pharmaceuticals), HMP Global (Editor-in-Chief, Journal of Invasive Cardiology), Journal of the American College of Cardiology (Guest Editor; Associate Editor), K2P (Co-Chair, interdisciplinary curriculum), Level Ex, Medtelligence/ReachMD (CME steering committees), MJH Life Sciences, Population Health Research Institute (for the COMPASS operations committee, publications committee, steering committee, and USA national co-leader, funded by Bayer), Slack Publications (Chief Medical Editor, Cardiology Today's Intervention), Society of Cardiovascular Patient Care (Secretary/Treasurer), and WebMD (CME steering committees); Other: Clinical Cardiology (Deputy Editor), NCDR-ACTION Registry Steering Committee (Chair), and VA CART Research and Publications Committee (Chair); Research Funding: Abbott, Afimmune, Amarin, Amgen, AstraZeneca, Bayer, Boehringer
Ingelheim, Bristol-Myers Squibb, Cardax, CellProthera, Cereno Scientific, Chiesi, CSL Behring, Eisai, Ethicon, Ferring Pharmaceuticals, Forest Laboratories, Fractyl, Garmin, HLS Therapeutics, Idorsia, Ironwood, Ischemix, Janssen, Lexicon, Lilly, Medtronic, MyoKardia, NirvaMed, Novartis, Novo Nordisk, Owkin, Pfizer, PhaseBio, PLx Pharma, Regeneron, Roche, Sanofi, Synaptic, The Medicines Company, and 89Bio; Royalties: Elsevier (Editor, Cardiovascular Intervention: A Companion to Braunwald's Heart Disease); Site Co-Investigator: Abbott, Biotronik, Boston Scientific, CSI, St. Jude Medical (now Abbott), and Svelte; Trustee: American College of Cardiology; Unfunded Research: FlowCo, Merck, and Takeda. Sami Z. Daoud is an employee and shareholder of AstraZeneca. Esther Garcia Gil was an employee and shareholder of AstraZeneca at the time of the study and is now an employee of Almirall S.A., Barcelona, Spain. Ferran Chuecos is an employee of AstraZeneca. Kenneth R. Chapman reports grants from Amgen, Baxter, GSK, and Shire, personal fees from CIHR-GSK Research Chair in Respiratory Healthcare Delivery (UHN) and Merck; grants and personal fees from AstraZeneca, Boehringer Ingelheim, CSL Behring, Genentech, Grifols, Kamada, Novartis, Roche, and Sanofi, during the conduct of the study.

Compliance with Ethics Guidelines. The trial protocol and informed consent procedures were approved by the Institutional Review Board, with controlling authority at each study site (see supplement). All patients provided written informed consent prior to the conduct of any study-specific procedures. The study was performed in accordance with the Helsinki Declaration of 1964 and its later amendments, along with Good Clinical Practice Guidelines.

Data Availability. The datasets generated during and/or analyzed during the current study are available through Vivli (https://vivli. org/), in accordance with AstraZeneca's datasharing policy (described at https:// astrazenecagrouptrials.pharmacm.com/ST/ Submission/Disclosure). 
Open Access. This article is licensed under a Creative Commons Attribution-NonCommercial 4.0 International License, which permits any non-commercial use, sharing, adaptation, distribution and reproduction in any medium or format, as long as you give appropriate credit to the original author(s) and the source, provide a link to the Creative Commons licence, and indicate if changes were made. The images or other third party material in this article are included in the article's Creative Commons licence, unless indicated otherwise in a credit line to the material. If material is not included in the article's Creative Commons licence and your intended use is not permitted by statutory regulation or exceeds the permitted use, you will need to obtain permission directly from the copyright holder. To view a copy of this licence, visit http://creativecommons.org/licenses/by$\mathrm{nc} / 4.0 /$.

\section{REFERENCES}

1. Global Initiative for Chronic Obstructive Lung Disease. Global strategy for the diagnosis, management, and prevention of chronic obstructive pulmonary disease. 2021. https://goldcopd.org/2021gold-reports/. Accessed 12 May 2021.

2. Lozano R, Naghavi M, Foreman K, et al. Global and regional mortality from 235 causes of death for 20 age groups in 1990 and 2010: a systematic analysis for the Global Burden of Disease Study 2010. Lancet. 2012;380:2095-128.

3. GBD 2017 Disease and Injury Incidence and Prevalence Collaborators. Global, regional, and national incidence, prevalence, and years lived with disability for 354 diseases and injuries for 195 countries and territories, 1990-2017: a systematic analysis for the Global Burden of Disease Study 2017. Lancet. 2018;392:1789-858.

4. Carter P, Lagan J, Fortune C, et al. Association of cardiovascular disease with respiratory disease. J Am Coll Cardiol. 2019;73:2166-77.

5. Selvaraj CL, Gurm HS, Gupta R, Ellis SG, Bhatt DL. Chronic obstructive pulmonary disease as a predictor of mortality in patients undergoing percutaneous coronary intervention. Am J Cardiol. 2005;96:756-9.
6. Donaldson GC, Seemungal TA, Bhowmik A, Wedzicha JA. Relationship between exacerbation frequency and lung function decline in chronic obstructive pulmonary disease. Thorax. 2002;57: 847-52.

7. Halpin DMG, Decramer M, Celli BR, Mueller A, Metzdorf N, Tashkin DP. Effect of a single exacerbation on decline in lung function in COPD. Respir Med. 2017;128:85-91.

8. Donaldson GC, Hurst JR, Smith CJ, Hubbard RB, Wedzicha JA. Increased risk of myocardial infarction and stroke following exacerbation of COPD. Chest. 2010;137:1091-7.

9. Halpin DMG, Decramer M, Celli B, Kesten S, Leimer I, Tashkin DP. Risk of nonlower respiratory serious adverse events following COPD exacerbations in the 4-year UPLIFT ${ }^{\circledR}$ trial. Lung. 2011;189:261-8.

10. Rothnie KJ, Yan R, Smeeth L, Quint JK. Risk of myocardial infarction (MI) and death following MI in people with chronic obstructive pulmonary disease (COPD): a systematic review and meta-analysis. BMJ Open. 2015;5: e007824.

11. Rothnie KJ, Connell $\mathrm{O}$, Müllerová $\mathrm{H}$, et al. Myocardial infarction and ischaemic stroke after exacerbations of chronic obstructive pulmonary disease. Ann Am Thorac Soc. 2018;15:935-46.

12. Suissa S, Dell'Aniello S, Ernst P. Long-term natural history of chronic obstructive pulmonary disease: severe exacerbations and mortality. Thorax. 2012;67:957-63.

13. Soler-Cataluña JJ, Martínez-García MA, Román Sánchez P, Salcedo E, Navarro M, Ochando R. Severe acute exacerbations and mortality in patients with chronic obstructive pulmonary disease. Thorax. 2005;60:925-31.

14. Rothnie KJ, Müllerová H, Smeeth L, Quint JK. Natural history of chronic obstructive pulmonary disease exacerbations in a general practice-based population with chronic obstructive pulmonary disease. Am J Respir Crit Care Med. 2018;198: 464-71.

15. Jones PW, Mahler DA, Gale R, Owen R, Kramer B. Profiling the effects of indacaterol on dyspnoea and health status in patients with COPD. Respir Med. 2011;105:892-9.

16. Vogelmeier C, Hederer B, Glaab T, et al. Tiotropium versus salmeterol for the prevention of exacerbations of COPD. N Engl J Med. 2011;364:1093-103.

17. Decramer ML, Chapman KR, Dahl R, et al. Oncedaily indacaterol versus tiotropium for patients with severe chronic obstructive pulmonary disease 
(INVIGORATE): a randomised, blinded, parallelgroup study. Lancet Respir Med. 2013;1:524-33.

18. Koarai A, Sugiura H, Yamada M, et al. Treatment with LABA versus LAMA for stable COPD: a systematic review and meta-analysis. BMC Pulm Med. 2020;20:111.

19. Lipson DA, Crim C, Criner GJ, et al. Reduction in all-cause mortality with fluticasone furoate/umeclidinium/vilanterol in patients with chronic obstructive pulmonary disease. Am J Respir Crit Care Med. 2020;201:1508-16.

20. Ferguson GT, Shaikh A, Tetzlaff K, Mueller A, Magnussen H, Watz H. Effect of inhaled corticosteroid withdrawal on chronic obstructive pulmonary disease exacerbations in patients taking triple therapy at baseline. Int J Chronic Obstruct Pulmon Dis. 2020;15:2879-88.

21. Singh S, Loke YK, Furberg CD. Inhaled anticholinergics and risk of major adverse cardiovascular events in patients with chronic obstructive pulmonary disease: a systematic review and metaanalysis. JAMA. 2008;300:1439-50.

22. Singh S, Loke YK, Enright PL, Furberg CD. Mortality associated with tiotropium mist inhaler in patients with chronic obstructive pulmonary disease: systematic review and meta-analysis of randomised controlled trials. BMJ. 2011;342: d3215.

23. Michele TM, Pinheiro S, Iyasu S. The safety of tiotropium-the FDA's conclusions. $\mathrm{N}$ Engl J Med. 2010;363:1097-9.

24. Verhamme KMC, Afonso A, Romio S, Stricker BC, Brusselle GG, Sturkenboom MCJM. Use of tiotropium Respimat Soft Mist Inhaler versus HandiHaler and mortality in patients with COPD. Eur Respir J. 2013;42:606-15.

25. Dong Y-H, Lin H-H, Shau W-Y, Wu Y-C, Chang C-H, Lai M-S. Comparative safety of inhaled medications in patients with chronic obstructive pulmonary disease: systematic review and mixed treatment comparison meta-analysis of randomised controlled trials. Thorax. 2013;68:48-56.

26. Wise RA, Chapman KR, Scirica BM, et al. Long-term evaluation of the effects of aclidinium bromide on major adverse cardiovascular events and COPD exacerbations in patients with moderate to very severe COPD: rationale and design of the ASCENT COPD study. Chronic Obstr Pulm Dis. 2018;5:5-15.

27. Wise RA, Chapman KR, Scirica BM, et al. Effect of aclidinium bromide on major cardiovascular events and exacerbations in high-risk patients with chronic obstructive pulmonary disease: the ASCENT-COPD randomized clinical trial. JAMA. 2019;321:1693-701.

28. Ernst P, Saad N, Suissa S. Inhaled corticosteroids in COPD: the clinical evidence. Eur Respir J. 2015;45: 525-37.

29. Halpin DMG, Birk R, Brealey N, et al. Single-inhaler triple therapy in symptomatic COPD patients: FULFIL subgroup analyses. ERJ Open Res. 2018;4: 00119-2017.

30. Ni H, Moe S, Soe Z, Myint KT, Viswanathan KN. Combined aclidinium bromide and long-acting beta2-agonist for chronic obstructive pulmonary disease (COPD). Cochrane Database Syst Rev. 2018;12: CD011594.

31. Rogliani P, Matera MG, Facciolo F, Page C, Cazzola M, Calzetta L. Beclomethasone dipropionate, formoterol fumarate and glycopyrronium bromide: synergy of triple combination therapy on human airway smooth muscle ex vivo. Br J Pharmacol. 2020;177:1150-63.

32. Rabe KF, Fabbri LM, Israel E, et al. Effect of ADRB2 polymorphisms on the efficacy of salmeterol and tiotropium in preventing COPD exacerbations: a prespecified substudy of the POET-COPD trial. Lancet Respir Med. 2014;2:44-53. 